\title{
How to Recruit and Retain Students using an Engineering Ambassador
}

Dr. Jeffrey Scott Bates, University of Utah

Karen J Krapcho, University of Utah

Karen J Krapcho, MS is the Outreach Coordinator for NSF grant \# 0652982 Utah's Engineers: A Statewide Initiative for Growth. Many of the programs discussed in this paper were funded (in part) from this grant.

Ms. Crystal Orantes, University of Utah 


\section{How to Recruit and Retain Students using an Engineering Ambassador Program}

\section{Introduction}

The mission of the Engineering Ambassador Program, in the College of Engineering at the University of Utah, is to recruit prospective students into engineering majors and to retain and graduate students who work as engineering ambassadors. The program, as implemented today, is a result of merging two existing programs: an NSF-funded mentor program and the Ambassador Program through the College of Engineering.

With a growing need for engineers in the United States, universities aim to enroll, retain, and graduate more engineering students so they may provide more active engineers for their community ${ }^{1}$. Through previous studies it has been found that students are more likely to be retained and graduate if they have a supportive peer group, social involvement, a good attitude toward engineering, and pre-college analytical skills ${ }^{1-4}$. The Engineering Ambassador Program aims to provide retention and more engineering graduates through all of these means. It does so by creating a community of engineering students who work together to recruit high school students to the field of engineering by providing them with awareness of engineering opportunities, academic advice, and analytical skills through hands-on activities. This program also benefits the ambassadors as it engages them in a learning community experience, which is known to provide their participants with practical competence, personal and social development, and deeper engagement ${ }^{5-6}$.

The ambassador program at the University of Utah has been built upon best practices and the success of similar programs at other large research universities. Various schools have already found success in recruiting students through K-12 mentor programs run by engineering students and faculty ${ }^{7-15}$. Furthermore, the program builds a community of engineering students. It has been shown that when students feel that they are part of a community they are more likely to be retained $^{16-21}$.

\section{The Ambassador Program Created by the College of Engineering}

The Ambassador Program was designed to give engineering students an opportunity to get involved with the College of Engineering. It was originally designed as a volunteer program where students would serve as ambassadors from the College of Engineering at events both in the community and on-campus. The program evolved to include a book scholarship as an incentive for participation in the program. Ambassadors were selected based on their academic standing and performance, and trained on ways to interact with students of varying abilities and attentions in a classroom setting. Their function was to relay the enthusiasm they demonstrated 
as they interfaced with prospective students, other K-12 students and educators. Furthermore, they provided the technical knowledge during the activities to help students understand the engineering concepts that were applied.

The Ambassadors were trained on how to give effective presentations, and each ambassador was charged with creating a presentation or activity that outlined their experience in engineering. One student enrolled in engineering because he had become involved with rocketry before college. He majored in mechanical engineering, and worked on a two-year senior design project where he and his team built a two stage rocket that was to be launched into legal space. He created a presentation about the history and physics of rocketry. Other students created presentations that explored each engineering major, while others helped create activities. One of the ambassadors worked at an internship at Kellogg's, where she designed processes for applying frosting to one of their products. She helped create a cookie processing activity where students work in teams to create uniform cookies with many other student contributors.

While the presentations and activities developed by the Ambassadors are still in use by the College of Engineering, it has been difficult replicating the same enthusiasm that the students demonstrated when the activities were first developed. They also did the minimum required to receive the book stipend and were not reliable when it came to prolonged activities such as Engineering Day and Engineering Week at the University of Utah. The Ambassadors have played an integral role in the development of activities and presentations that help address what students learn in the science and math curricula in the K-12 schools.

\section{The NSF Mentor Program Created by a Group of Faculty}

The NSF-sponsored mentoring program began in 2007 with a grant to increase the number of engineering graduates in the state. A significant component of this grant was designated to develop an outreach group in each department in the College of Engineering as well as a small team of students from the local 2-year community college. These teams of undergraduates were assembled by a group of faculty members representing each department in the College of Engineering and tasked with developing hands-on activity modules highlighting each engineering department ${ }^{22}$. The mentors were asked to create modules that applied what they learned in high school to their current field of study. The activities needed to correspond to learning objectives required by the state curricula. The student teams visited high school classes, typically math, biology, chemistry and physics to introduce the students and teachers to engineering and did hands-on activities. The NSF-sponsored mentors were paid \$11 to \$14 per hour, depending on their year in school, to participate in the program. Initially the teams were small, consisting of three to four undergraduates per department; however, by 2011 some of the teams had grown as large as 14 students per team. The number of students involved in the program is given in Table 1. 
Table 1. Enrollment in the NSF Mentor Program from 2007 through 2014

\begin{tabular}{|l|l|l|l|l|l|l|l|}
\hline \multicolumn{7}{|c|}{ NSF-sponsored Undergraduate Mentors } & \multicolumn{2}{l|}{ Combined Program } \\
\hline & $2007-8$ & $2008-9$ & $2009-10$ & $2010-11$ & $2011-12$ & $2012-13$ & $2013-14$ \\
\hline $\begin{array}{l}\text { University of } \\
\text { Utah }\end{array}$ & 35 & 42 & 50 & 60 & 68 & 27 & 17 \\
\hline $\begin{array}{l}\text { Salt Lake } \\
\text { Community } \\
\text { College }\end{array}$ & 4 & 1 & 1 & 5 & 6 & -- & -- \\
\hline
\end{tabular}

In addition to classroom visits, the cohort of undergraduate mentors provided support for a multitude of community outreach activities. These included on-campus events such as Engineering Day and Meet an Inventor Night, as well as science nights at schools and libraries. The outreach teams have provided demonstrations and activities for MESA clubs, helped to organize a Girl Scout Night, and developed a robotics badge for a Boy Scout Pow-Wow. While the original goal of the program was to educate teachers about real-life applications of what they were teaching and recruit high school students to the field of engineering, the current objectives have expanded to include the following:

- Helping others in the community to develop a personal connection with engineering

- Developing presentation and leadership skills

- Increasing awareness of engineering and types of engineering majors

- Cohort formation to facilitate college retention and improve graduation rates

\section{Merging the Programs}

The Engineering Ambassador Program and the NSF Mentor Program coexisted autonomously for several years. As the NSF grant was nearing its end, coordinators for both programs joined forces to create a sustainable program with which the College could continue forward. The two programs were merged, and the resulting program is called the Engineering Ambassador Program. This program includes two or three students from each department, which is fewer than the number employed through the NSF grant. In addition, the departmental teams are less distinct as the Engineering Ambassadors meet as a whole group, rather than in individual departments. Subcommittees have been established for students to contribute to initiatives within the College of Engineering, including the first-year experience, transfer student success, summer camp coordination and development, lesson plan development, and diversity initiatives. The Ambassadors still bring modules out to high school classes and promote engineering at community events; however, they also serve as a focus group for opinions and initiatives on retention issues. The current group of ambassadors is a varied group with high percentages of female (70\%) and ethnically diverse (60\% non-Caucasian) students. The majority of the applicants for the ambassador positions are ethnic females, a disproportionate 
representation of the student population in the College of Engineering, a low percentage of female students and minorities, $15 \%$ and $11 \%$, respectively ${ }^{23}$.

\section{Ambassador-Led Activities}

There are several programs that the Engineering Ambassadors have been assigned. These include Meet an Inventor Night, activity development, the Exploring Engineering summer camp and service as student representatives at events coordinated by the College of Engineering, including recruitment events, and parent nights, among others.

Meet an Inventor Night was designed as a follow-up event to the annual Engineering Day event. Students who have signed up to receive additional information from the College of Engineering, or who have attended Engineering Day are invited to attend this event which occurs in the spring coinciding with the time that high school seniors are making their choices about college. The focus of the night is to introduce prospective students and their parents to concepts relating to bringing ideas to reality through engineering design and invention. The night begins with a guest lecturer who presents information on their research and development and strives to inspire students to think outside of the box. The speaker is followed by breakout sessions that include hands-on activities where students work on a small-scale design project, test their design, and make modifications as needed. This gives students exposure to prototyping. Another breakout session option is to attend a panel discussion that includes patent attorneys, professors who have commercialized their research and engineering alums who work both in research and development and for small companies that help people develop new technologies. The evening ends with a mingling event designed to give attendees the opportunity to interact with people who create and invent new technologies. The Engineering Ambassadors help coordinate the event by planning and developing new activities and finding people from the university and community to participate as inventors.

In addition to developing new activities for Meet an Inventor Night, the Engineering Ambassadors are working to assemble check-out kits based on the modules that are used in classrooms. These activities are documented in the form of written lesson plans, presentation slides, handouts and worksheets and tutorial videos that help educators prepare for the activities that they will run in their classrooms. The Engineering Ambassadors provide valuable background information to educators who do not have a background in engineering, as well as meaningful ties to the curriculum that is taught in the classroom. This program has been a valuable resource to teachers because the lesson plans have not been designed to compete with the curriculum, but rather to serve as a resource for providing meaningful, hands-on activities that teachers can adapt for their classrooms.

The Engineering Ambassadors are an essential part of the Exploring Engineering Camp. Representatives from each department work with the camp director to develop and implement 
camp activities that highlight each engineering department and tie into the overall camp theme. Themes in the past have included Engineering a Greener Planet; Lights, Camera, Engineering, and BioInnovations.

In addition to these activities, there are a variety of events held both on and off-campus where personnel have been requested from the College of Engineering. The majority of these events are designed to either recruit prospective students or help students who are already admitted to choose which engineering major they will study. Because representation from the College of Engineering does not always include personnel who are well-versed in academic advising and content taught in the classroom, Engineering Ambassadors serve as a valuable resource during these community events because they have been trained to discuss each engineering major offered at the University of Utah, and can share their experiences with prospective students and their families.

\section{Real-World Applications}

As mentioned in the previous section, Engineering Ambassadors are able to share their experiences with academic advising and in-class learning. While Engineering Ambassadors are not academic advisors, they can share general information on the courses taken for some of the engineering majors. In addition, Engineering Ambassadors contribute a great deal to the activities and presentations in the classroom. For example, one activity presents information on civil engineering, and then students work in teams to build a skyscraper with household materials that can withstand an earthquake. When non-civil engineers facilitate this presentation and activity, it runs smoothly. Professional staff are not well versed in structural engineering, and may not be completely interested in learning more. The activity runs well without Engineering Ambassadors; however, when this activity is facilitated with an Engineering Ambassador studying civil engineering, the activity takes on a new level because the student can share what was learned in her coursework about structural engineering. In addition, she has the enthusiasm that is needed to make this a motivational activity that may encourage students to study civil engineering.

Engineering Ambassadors a unique perspective when discussing the career outlook with prospective students. Talking to high school students helps them process what they are learning in their degree program, and helps them identify potential careers that would be of interest to them. While they do not have experience working as engineers, their enthusiasm about engineering and projects they have worked on may help others see this as a possible college major and future career choice.

\section{Enrollment at the University}

As stated in the introduction, our engineering ambassador programs have been an integral part of increasing the enrollment of students in the College of Engineering (COE). Enrollment 
has increased nearly $60 \%$ since the 2007-8 academic year while the overall enrollment at the University of Utah during this same period has only increased $14 \%{ }^{23}$. The number of BS degrees awarded by the COE during this same time frame has increased $28 \%{ }^{23}$.

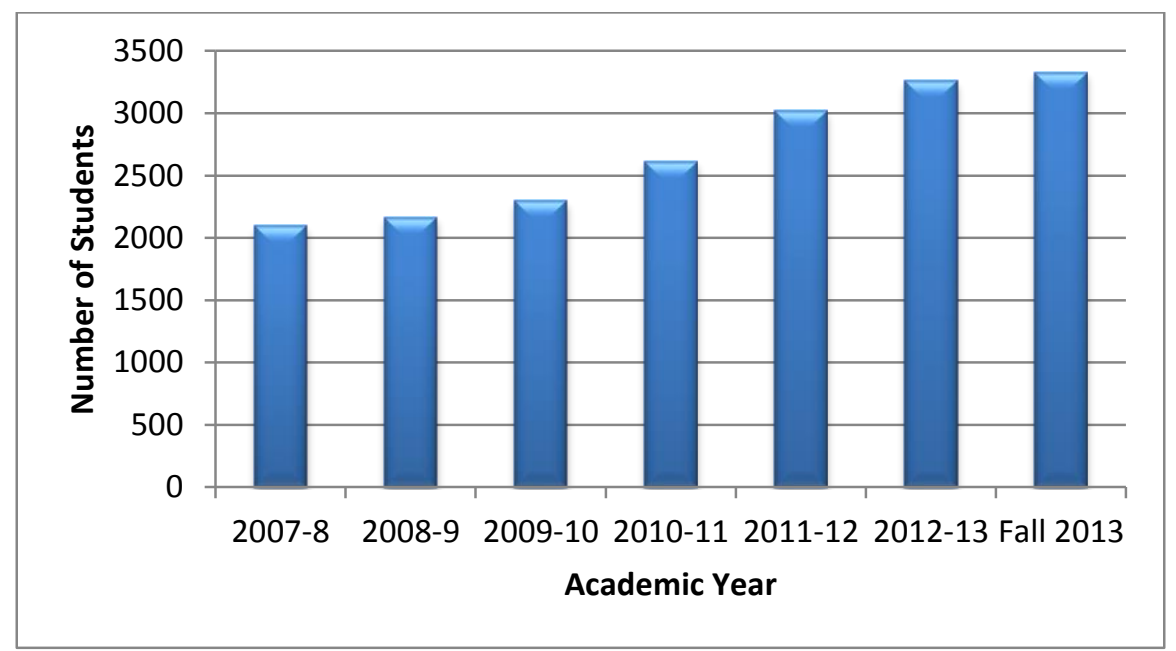

Figure 1. Increases in Enrollment in the College of Engineering (majors and pre-majors)

\section{Data Collected from High School Students}

During the first few years of the NSF grant, mentor teams surveyed the high school students in the classes they presented in order to see if their presentations helped the high school students become more familiar with engineering and more likely to choose engineering as a career. Nearly 1000 surveys were collected. Of approximately 2500 high school student responses gathered from the outreach teams from 2007 to 2010, 74\% responded that they were now more familiar with engineering, $68 \%$ said that they could see how their classes related to engineering, $62 \%$ thought that engineering seemed more exciting and $42 \%$ were more likely to pursue engineering than they were before the presentations ${ }^{25}$. These in-class surveys were discontinued in 2010 .

\section{Data Collected from Undergraduate Students}

A survey was sent to the Engineering Ambassadors to evaluate the impact of the program on the recruitment and retention of students in the program. The survey was designed to address the following:

- The type of student that participates in outreach programs

- How they became interested in engineering

- The level of their engagement in outreach and other community involvement

- Retention of students in engineering majors

- Other non-academic interests

- Post-graduate plans 
A link to an online survey was sent to all current and former students enrolled in the Ambassador Program, the NSF Mentor Program or the Engineering Ambassador Program. Of the 37 respondents to the survey, $57 \%$ were male, $43 \%$ were female, 12 were current ambassadors and 25 were former ambassadors. The median participant in the program was enrolled in their second year of an engineering program when they started, and participated for two years. Many of the participants took advanced placement courses in high school with the number of AP classes ranging of 0 to 8 with the median being 3 and a mean of 3.7.

Ambassadors were asked about their reasons for choosing engineering. The results given in Figure 1 suggest that the top three reasons include an interest in math and science in high school, the potential for a good job with a good salary, and a career in which they can make a difference. All of these are messages are conveyed to high school students that participate in outreach activities.

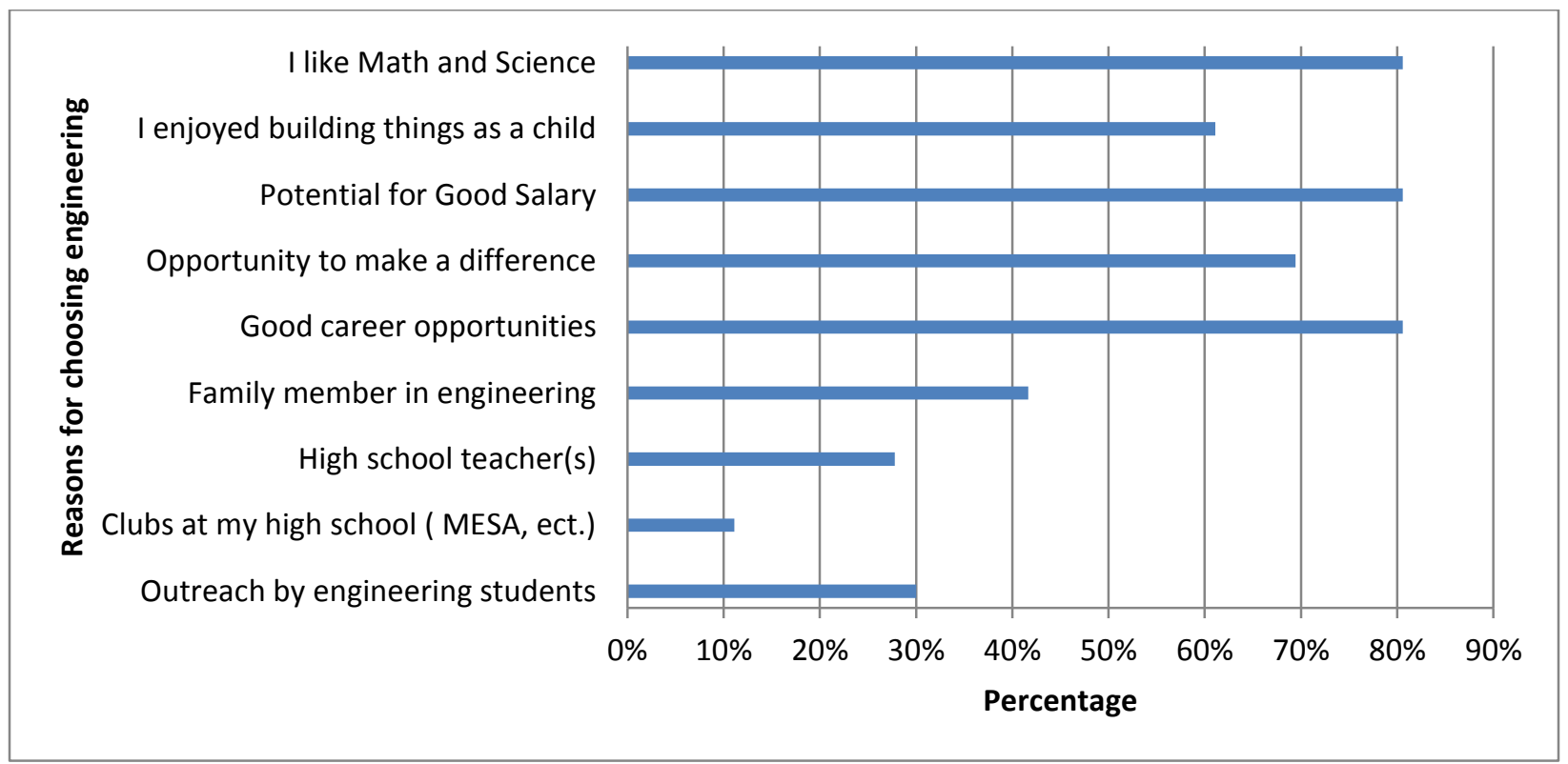

Figure 2. Responses given by Engineering Ambassadors for choosing to major in engineering

Nearly $80 \%$ participated in extracurricular activities in high school and $30 \%$ participated in community programs such as the Boy scouts, 4-H, church groups and the Boys and Girls Club. These same students continue to be involved in college, seeking out student clubs and continuing with their community involvements. These results are given in Figure 2. After their college graduation, many have continued their involved in community activities such as church, Boys and Girls Clubs, the food pantry, and many others. Furthermore, many have gone on to become active in professional organizations such as IEEE, AIChE, AICE and AISES. 


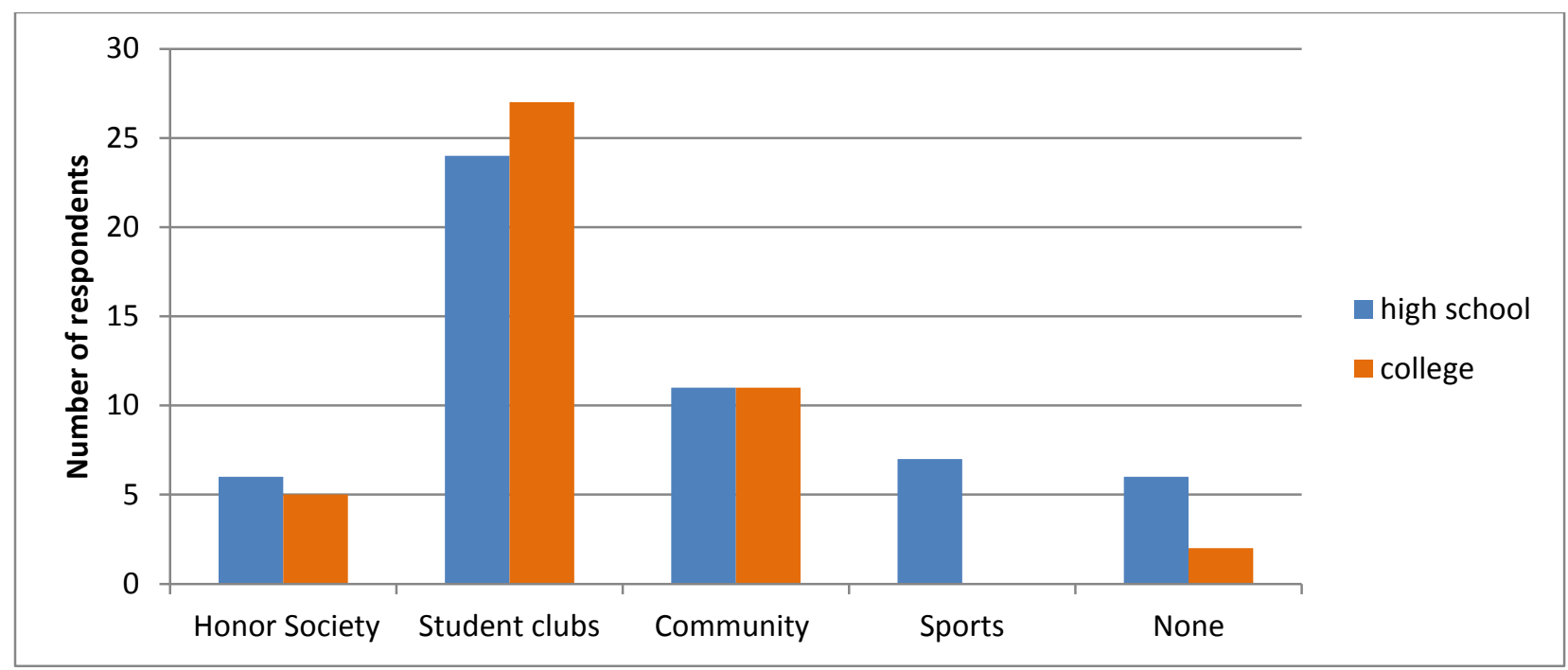

Figure 3. Engineering Ambassador involvement in extracurricular activities

When asked of their plans after receiving their undergraduate degree in engineering, more than $80 \%$ indicated an interest in graduate programs. The results are given in Figure 3.

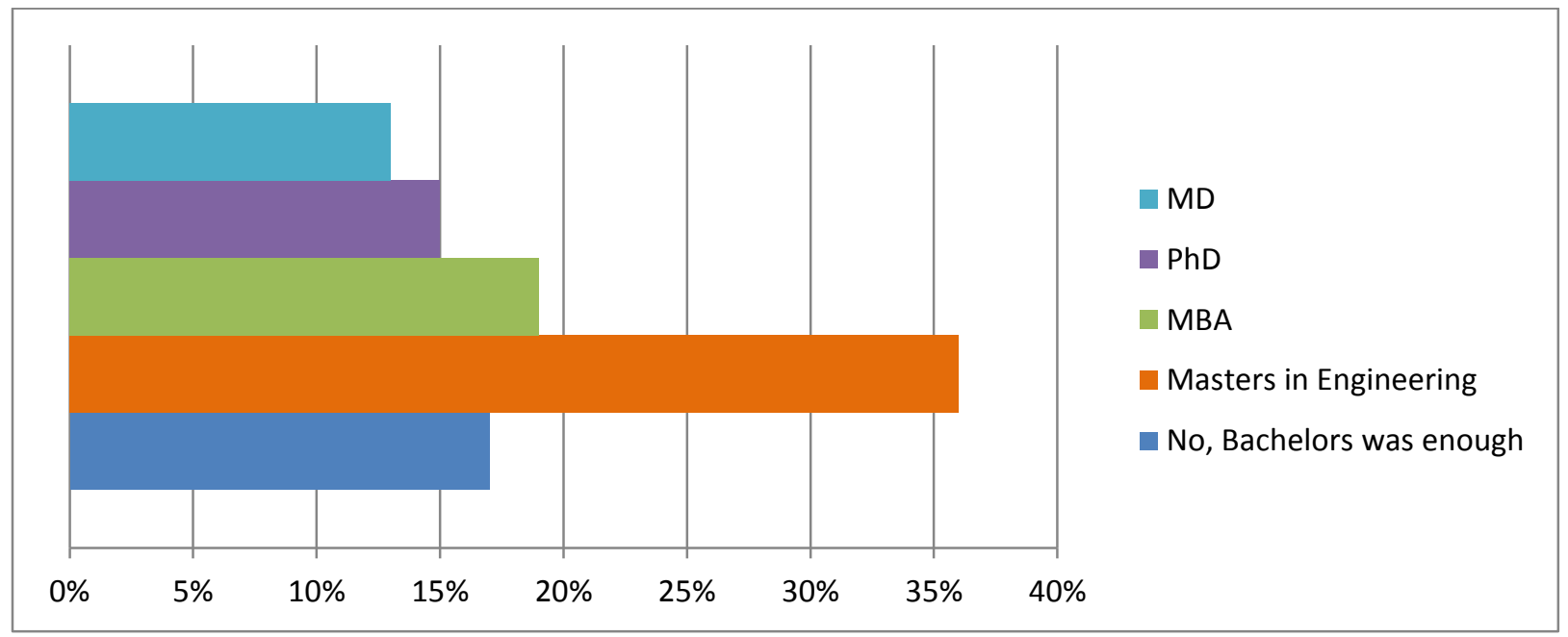

Figure 4. Engineering Ambassador interest in pursuing a graduate degree

\section{Benefits of Program}

Respondents were asked to evaluate the impact of participating in the ambassador program. They were asked to comment on how often they considered changing their major prior to and since becoming ambassadors. The results given in Figure 4 show that participating in the program helped them make a commitment to engineering as they doubted their choice in major less often. 


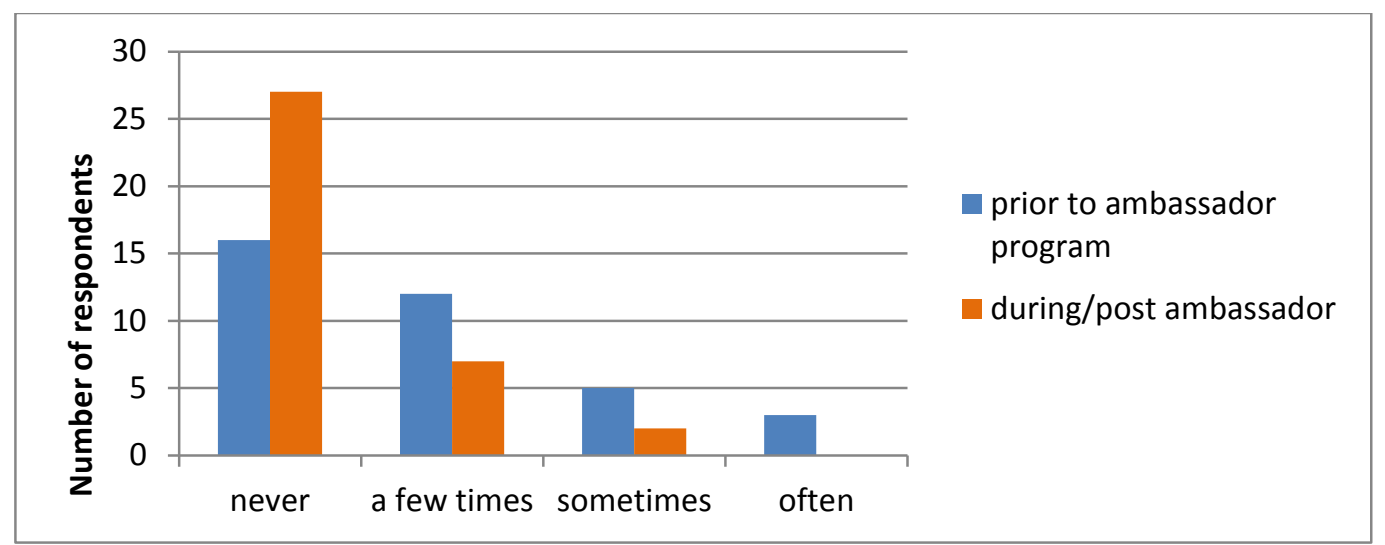

Figure 5. Responses to how often Engineering Ambassadors consider changing their major

When asked to rank the benefits of being an ambassador respondents reported that the primary benefit of participating in the program was helping high school students learn about engineering. Other common answers include a sense of accomplishment from being involved, improved presentation skills, and social connections. Some comments from Engineering Ambassadors include the following:

- I really enjoyed mentoring students to learn more about engineering

- It helped me better understand material as I presented it to others

- This program helped me become more talkative to strangers

- It helped me gain presentation skills, organizational skills, and leadership skills

- The program helped me make connections, made me feel part of the school and break out of my shell

- I made good friends and learned how to take constructive criticism

- I learned more about opportunities in the field of engineering and learned to love my education even more

- I have been able to network a lot in this job and become aware of a bunch of opportunities offered here at the university

Engineering Ambassadors were asked about the benefit of being paid for the program. The ability to receive compensation was an initial incentive for applying to the program; however, once the Engineering Ambassadors began their work, many of them said they would be involved without pay. Furthermore, when asked about the downsides of the program, there were no responses listed.

\section{Personal Experiences of Two Engineering Ambassadors}

Two of the Engineering Ambassadors shared their experiences with the Engineering Ambassador program as a result of benefitting both as a high school student as well as an Engineering Ambassador. Their experiences are shared below:

1. During my junior year of high school I attended the first annual engineering summer camp held at the University of Utah. It was there that I was first introduced to the 
major I have pursued, Biomedical Engineering. Even though my dad is an engineer, I did not have knowledge of this degree up until this point. Through this summer camp I was introduced to it, and that played a large role in me deciding to pursue it.

During my first semester at the University of Utah, I became an ambassador. Through this program I had the opportunity to learn more about how the education process works, and gained access to upperclassmen that served as mentors to me during my first two years of college. Through them I learned what to expect in my classes in the coming years. An additional benefit was improvement of presentation skills through the program. When I started the program I was a nervous presenter but after a couple of years I became more comfortable presenting while I was performing both ambassador duties and in class. This is a big benefit as I had to present more and more in class as I began to take upper level courses. One more benefit was forming connections with faculty. Through this position, I have formed a great connection with a professor in my department who has been able to write me several letters of recommendation that have successfully helped me obtain scholarships.

2. My high school junior and senior year summer breaks were full of the engineering camps run by past Ambassadors at the University of Utah. This was my first interaction with engineering and the university, which played a fundamental part in my pursuit of Civil Engineering. Through past Ambassadors I felt connected to the university and the College of Engineering. During my second semester I became a part of the Ambassador team which helped me feel like I contributed by sharing my passion for engineering with prospective students. I have also gained leadership skills through presentations and subcommittee duties.

The greatest benefit I have seen with the Ambassador program is helping others. I have accomplished a great deal, and will be graduating in May 2014 with the support of the College of Engineering and mentors that I have met through the Ambassador Program. With their support and guidance, I am applying to Graduate School in Civil Engineering to do research in Materials of Nuclear Structures. I am a first generation college student and have found my higher education to be very foreign to my family and myself, but where I lacked support to continue education I found through other mentors in the Ambassador Program.

The Ambassador program not only helps during years in college but has benefited me by having past ambassadors currently out in the workforce. They have now become mentors to me as I continue my path, knowing that support system just grows and disperses throughout disciplines and locations. The ambassador program is a support system for many generations starting from past ambassadors to current elementary students. We benefit by having the ability to touch the lives of the future faces of engineering. 
While the Engineering Ambassador Program is a benefit to the community by providing information to high school students as well as resources for teachers, the program has provided benefits to the Engineering Ambassadors through helping them apply classroom learning through teaching, providing them with the motivation they need to continue their enrollment in engineering majors, and through creating a strong sense of community volunteerism through both organized and unorganized opportunities.

\section{Conclusion}

The Engineering Ambassador Program in its current form has not only evolved from two separate programs, but has also evolved over time to best address and meet the needs of both the community it serves and the current engineering students. The overall charge of the program is to educate the community about opportunities in engineering by providing hands-on activities geared toward high school-age students and classroom resources for educators to use at their discretion in conjunction with the state core curriculum. While the benefit to high school students has been evident in the increase in enrollment in engineering programs, the Engineering Ambassadors have also benefitted by increasing their interest in engineering, converting their classroom learning into teaching opportunities, and through an increased retention in college and in their chosen engineering major. As mentioned, pay was an initial incentive for Engineering Ambassadors, but once they began working in the program, students said they would participate regardless of a monetary reward. While there are still areas for improving the program, the Engineering Ambassador Program has become a highly valued program at the institution it serves.

\section{References}

1. Veenstra, Cindy P., Eric L. Dey, and Gary D. Herrin. "A Model for Freshman Engineering Retention." Advances in Engineering Education Winter (2009): 1-33.

2. Braxton, John M. "Linking Learning and Leaving." Reworking the Student Departure Puzzle. Nashville: Vanderbilt UP, (2004): 85-88.

3. Zhao, Chun-Mei, and George D. Kuh. "ADDING VALUE: Learning Communities and Student Engagement." Research in Higher Education 45.2 (2004): 115-38.

4. Lotkowski, V.A., S.B. Robbins, and R.J. Noeth. "The role of academic and non-academic Factors in improving College retention." ACT, Inc., (2004).

5. Zepke, Nick, and Linda Leach. "Improving Student Engagement: Ten Proposals for Action." Active Learning in Higher Education 11.3 (2010): 167-77.

6. Coates, H., Hillman, K., Jackson, D., Tan, L., Daws, A., Rainsford, D., \& Murphy, M. (2008). Attracting, engaging and retaining: New conversations about learning. Australasian student engagement report (AUSSE). Camberwell: ACER.

7. Sullivan, J. F., Davis, S. E., Derazia, J. L., and Carlson, D. W. "Beyond the pipeline: Building a K - 12 engineering outreach program." Frontiers in Education Annual Conf., Institute of Electrical and Electronics Engineers, New York (1999).

8. Tsang, E., and Newman, E. J. “'Service-learning's effect on engineering students and K-12 teacher partnership in an 'Introduction to Mechanical Engineering' course. Frontiers in Education Annual Conf., 
Institute of Electrical and Electronics Engineers, New York (1998).

9. Wilson, D. M., and Chizeck, H. "'Aligning outreach with cognitive development: $\mathrm{K}-12$ initiatives in electrical engineering at the University of Washington.' Frontiers in Education Annual Conf., Institute of Electrical and Electronics Engineers, New York (1999).

10. Genalo, L. J., Wright, C. T., and Wright, K. B. "Toying with technology in elementary education.' Frontiers in Education Annual Conf., Institute of Electrical and Electronics Engineers, New York (1998).

11. Bottomley, L. J., Parry, E. A., Washburn, S., Hossain, A., and Meyer, R. "Engineering students in K - 12 schools." ASEE Annual Conf., American Society for Engineering Education, Washington, D.C (2000).

12. Carroll, D. R. "Bridge engineering for the elementary grades." J. Eng. Educ., 86(3), (1997): 227-231.

13. Demetry, C., and Nicoletti, D. W. "Camp REACH: An engineering summer camp for middle school girls." Frontiers in Education Annual Conf., Institute of Electrical and Electronics Engineers, New York (1997).

14. Hannan, J., et al. "An engineering design summer camp for a diverse group of high school students." Frontiers in Education Annual Conf., Institute of Electrical and Electronics Engineers, New York (1997).

15. Ondracek, R. P., and Leslie-Pekecky, D. "ScienceWorks: A university-based science outreach group." ASEE Annual Conf., American Society for Engineering Education, Washington, D.C (1999).

16. Akl, R., Keathly, D., and Garlick, R., "Strategies for Retention and Recruitment of Women and Minorities in Computer Science and Engineering."

17. Murtaugh, Paul A., Leslie D. Burns, and Jill Schuster. "Predicting the Retention of University Students" Research in Higher Education 40.3 (1999): 355-71.

18. Astin, A. W. What Matters in College: Four Critical Years Revisited. San Francisco: Jossey-Bass (1993).

19. Tinto, V. Leaving College: Rethinking the Causes and Cures of Student Attrition. Chicago: The University of Chicago Press (1993).

20. Naretto, J. A. Adult student retention: The influence of internal and external communities. NASPA Journal 32 (1995): 90-97.

21. Bean, John, and Shevawn B. Eaton. "The Psychology Underlying Successful Retention Practices." Journal of College Student Retention: Research, Theory and Practice 3.1 (2001): 73-89.

22. Bates, J.S., Leonard, D.E., and Krapcho, K.J. "Creating a Space for Engineering in the K-12 Curriculum," ASEE Rocky Mountain Section Conference Proceedings (2013): 1-6.

23. Office of Budget and Institutional Analysis, University of Utah, 2013

24. Krapcho, K.J. and Furse, C.M. "Lessons Learned Developing and Engaging Engineering Summer Camp," ASEE Annual Conference, Indianapolis (2014).

25. Richerson, Furse and Bergerson, University Partnership with High School Teachers to Increase Student Awareness of Engineering, ASEE (2011). 